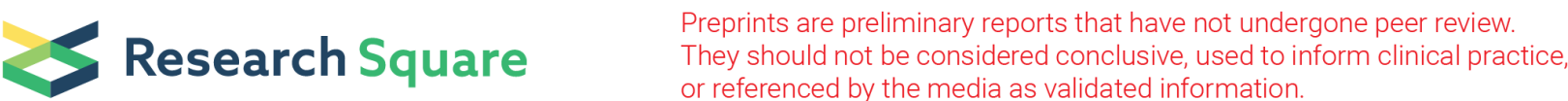

\section{Mental Health and Community-Based Rehabilitation: A Qualitative Description of the Experiences and Perspectives of Service Users and Carers in Bangladesh}

\section{Kamrun Nahar Koly ( $\nabla$ koly@icddrb.org )}

International Centre for Diarrhoeal Disease Research Bangladesh https://orcid.org/0000-0003-2466-

8139

Fahima Akter Shammi

North South University

Rehnuma Abdullah

North South University

Taslima Akter

Centre for Disability in Development

Tasdik Hasan

University of Liverpool

Julian Eaton

London School of Hygiene and Tropical Medicine

Grace Ryan

London School of Hygiene and Tropical Medicine

\section{Research}

Keywords: CBR, mental health, qualitative research, Bangladesh

Posted Date: August 26th, 2020

DOI: https://doi.org/10.21203/rs.3.rs-59455/v1

License: (c) (1) This work is licensed under a Creative Commons Attribution 4.0 International License.

Read Full License

Version of Record: A version of this preprint was published on March 8th, 2021. See the published version at https://doi.org/10.1007/s10597-021-00790-0. 


\section{Abstract}

\section{Background}

Since 2016, Promotion of Human Rights of Persons with Disabilities in Bangladesh (PHRPB) has been working to include people with psychosocial disabilities in their community-based inclusive development work, and to increase access to formal mental health care.

\section{Methods}

Field visits were carried out to PHRPBD catchment areas in Dhaka and Chittagong for a case study on the integration of mental health into community-based rehabilitation (CBR). This paper synthesizes the results of twenty-five semi-structured interviews carried out as part of the case study. Participants included people with psychosocial disabilities, intellectual disabilities, epilepsy or other cognitive impairments and their carers as needed. Interviews were audio-recorded, transcribed and translated from Bangla to English, then hand-coded for content analysis.

\section{Results}

Results were organized into five overarching categories: (1) explanatory models, (2) help-seeking behaviors, (3) impact of services, (4) challenges and barriers to improving mental health, (5) recommendations of users and carers. Respondents either had no explanation for why service users had become unwell or attributed it to physically and/or emotionally traumatic events or supernatural causes. Before attending PHRPBD's mental health services, most had visited formal or informal health care providers, often with disappointing results. Despite positive feedback on PHRPBD's services, participants identified ongoing challenges. Stigma, discrimination and human rights abuses persist and are compounded by issues of gender inequality. Participants also identified barriers and made recommendations specific to the program itself, mainly regarding accessibility (e.g., cost, distance, frequency).

\section{Conclusions}

This study adds to the limited body of qualitative research on mental health in Bangladesh, reinforcing previous findings on explanatory models and health-seeking behaviors while providing new insights into the impact of a CBR program in this context. Feedback of service users and carers suggests that CBR may indeed be a useful approach to increase access to services in Bangladesh for people with psychosocial or intellectual disabilities, epilepsy or other cognitive impairments. However, this program is not without its limitations, some of which are the product of broader issues within the mental health system and others of the social and cultural context. More research is needed to formally evaluate this and other CBR programs in the Global South.

\section{Background}


The eighth most populous country in the world, Bangladesh has been praised for substantial progress in health and development $(1,2)$. Bangladesh met several Millennium Development Goal targets, including a two-thirds reduction in under-five mortality between 1990-2015 (3). Also in 2015, Bangladesh was reclassified by the World Bank as a lower middle-income country, and by 2024 is expected to graduate from the United Nations Least Developed Countries List (1).

However, as observed by Chowdhury et al. in their 2013 Lancet series on innovation for universal health coverage in Bangladesh, "The country presents a puzzling paradox of substantial mortality reductions alongside uneven health burdens" (pp. 1734) (2). Among the most overlooked of these "health burdens" is that of mental health. In Bangladesh, depression alone is the third biggest contributor to years lived with disability (a key metric for the calculation of the Global Burden of Disease) (4). A 2018 survey by the National Institute of Mental Health found that of the approximately $17 \%$ of adults in Bangladesh who have common mental health conditions such as depression, $92.3 \%$ do not receive medical attention (5). This survey also estimated adult prevalence rates for severe mental health conditions, which are less common but often more disabling: schizophrenia and other psychotic disorders were estimated at $1 \%$; bipolar disorder at $0.4 \%$; substance use and self-harm $0.2 \%$; neurodevelopmental and neurocognitive disorders $0.3 \%$; and personality disorders $0.1 \%(5)$.No estimates of access to mental health care among people with severe mental health conditions were reported, though this is also expected to be low (6).

The specialist mental health workforce available to care for people with mental health conditions is extremely limited, even in comparison to other countries in the region. According to the World Health Organization (WHO) the Southeast Asian region has 2.5 mental health workers (including 0.4 psychiatrists and 0.1 psychologists) available for every 100,000 people(7). Bangladesh, in contrast, has 1.17 (0.13 psychiatrists, 0.12 psychologists)(8). Most of these mental health workers are based in urban areas $(6,9,10)$, while $85 \%$ of the country's population live in rural areas(11). Similarly, the small number of tertiary government hospitals that provide mental health care are generally located in urban areas( 10 , 12), and mental health has not yet been integrated into Bangladesh's primary care system (9). In 2015, only $0.44 \%$ of Bangladesh's 2.3 billiondollar national health budget was allocated to mental health $(9,13)$.

While the horizontal integration of mental health into other areas of health and social care has long been identified as a priority in global mental health (14), for countries like Bangladesh this strategy is especially promising. By helping other comparatively strong systems to better meet the needs of people with mental health conditions, Bangladesh can compensate for some of the limitations of its mental health system while also providing more holistic and comprehensive care than is perhaps feasible with vertical services alone. However, there are few documented examples of how this can be done in Bangladesh.

Community-Based Rehabilitationand PHRPBD 
Promoted by the WHO for nearly forty years, Community-Based Rehabilitation (CBR) is a strategy to improve access to services for people with disabilities that aims to make optimal use of local resources. The 2010 WHO CBR guidelines included a special supplement on mental health, which drew mainly from experience, evidence in community mental health, and basic development principles, to make recommendations for the integration of support for people with psychosocial disabilities into CBR programmes(15). Since then, different organizations taking a CBR approach have started to integrate mental health into their work in low- and middle-income countries (16).

Part of an initiative by the international disability-inclusive development organization CBM and the Bangladeshi disability rights organization Centre for Disability in Development (CDD), the Promotion of Human Rights of Persons with Disabilities in Bangladesh (PHRPBD) program began including people with psychosocial disabilities in its activities in 2016(17). People with psychosocial disabilities were identified via community surveys, included in self-help groups for people with disabilities, and invited to annual mental health camps organized by PHRPBD in collaboration with Bangladeshi psychiatrists. Through the self-help groups and with the support of trained local field staff, PHRPBD takes a mainstreaming approach focused on ensuring that people with disabilities have access to education, employment, healthcare and other rights and opportunities on an equal basis with others in their communities. To improve access to mental healthcare specifically, psychiatrists travel to community meeting-spots in PHRPBD catchment areas for mental health camps, where they can make diagnoses and prescribe medications, some of which are subsidized by the program.

As part of a case study of PHRPBD carried out in 2019, semi-structured interviews were conducted with service users identified by the program as having psychosocial or intellectual disabilities, epilepsy or other cognitive impairments, as well as with some of their carers. Recognizing the richness of the interview data and the relative dearth of qualitative studies on mental health in Bangladesh (6), we decided to undertake a more in-depth analysis of these interviews, to better understand and document the lived experiences of service users and carers generally as well as their perceptions of and recommendations for this particular program.

\section{Methods}

This is a qualitative descriptive study(18)analyzing results of interviews with service users and carers that were carried out as part of a multi-method case study of PHRPBD following the Case Study Methodology to Monitor and Evaluate Community Mental Health Programs in Low- and Middle-Income Countries(19). Interviews took place over the course of a two-week field visit by the last author (GR). Ethical approvals were secured from the London School of Hygiene and Tropical Medicine (Ref. 14597) and the Bangladesh Medical Research Council (Ref. 14826092018) before any data were collected.

Setting

PHRPBD is currently being implemented across nine districts of Bangladesh by eight partner organizations and serves people with all different types of disabilities, including physical and sensory 
disabilities as well as psychosocial disabilities and others. The Dhaka and Chittagong divisions were selected for this study to enable sampling from a range of urban, semi-urban and rural settings within two discrete catchment areas in different parts of the country. Interviews were carried out either in participants' homes or at self-help group meeting locations.

Sample

We used purposive sampling in consultation with staff of PHRPBD and local partner organizations to identify a diverse sample of service users participating in the program's self-help groups and/or mental health camps. When service users were under the age of 18 or unable to speak on their own behalf, their carers (usually family members) were interviewed. After removing two interviews on the basis of poor sound quality, interviews with nine service users and 16carers were included.

Service users mostly had psychosocial disabilities, though CBR programs like PHRPBD generally focus on the types of impairments and barriers experienced by potential participants rather than on specific diagnoses. Consequently, several of the service users identified by PHRPBD for inclusion in this study had epilepsy, intellectual disabilities or other cognitive impairments due to stroke, head injury or unknown causes. As they were considered by the program to be beneficiaries of PHRPBD's mental health work, they were not excluded from the sample.

Data Collection

A semi-structured interview guide was developed based on the relevant domains of the Case Study Methodology and field-tested through a prior visit to a community-based rehabilitation (CBR)program in Akwalbom, Nigeria(20). The interview guide was translated from English to Bangla by a bilingual translator with experience in health research [See Appendix for English and Bangla versions]. A bilingual PHRPBD staff member (TA) worked with the international interviewer (GR) to ask interview questions and probe for further information as needed. In a few cases where there were dialectical differences between the translator and the interview participants, a member of the local PHRPBD field staff was asked to assist. With permission, interviews were audio-recorded for transcription.

Data Management

Audio-recordings were transcribed in Bangla and then translated into English by four research students under the supervision of the first author (KK), an experienced bilingual health researcher independent from the program. Translations were independently quality-checked by another independent student researcher $(\mathrm{LH})$ and the first author.

\section{Data Analysis}

A content analysis was carried out using a combination of inductive and deductive techniques. Analysis was led by the first author and supported by two student researchers, with guidance from the last author. 
During a preliminary phase of data immersion, the two student researchers (FS \& RA) read and re-read the transcripts, noting any observations as memos and developing an initial coding framework, alongside representative quotes. The coding framework was reviewed by the last author and compared to the initial interview guide, in order to finalize the codes for analysis. Transcripts were then hand-coded by the two coders, and all relevant quotes were excerpted under their respective codes. Any differences in coding were discussed between the two coders until a resolution could be reached. Results are summarized below with representative quotes included for illustration, to provide a qualitative description.

\section{Results}

\section{Participant Characteristics}

Interview data was collected for 25service users (11 male, 14 female), including 18 with psychosocial disabilities, two with intellectual disabilities, two with epilepsy and three with other cognitive impairments resulting from a stroke, a head injury, or an unknown cause. The mean age of service users was 29.6 (range 17-56) [Table 1].

Table 1

Characteristics of service users included in study

\begin{tabular}{|lllll|}
\hline & \multicolumn{2}{l}{ Chittagong } & \multicolumn{2}{l|}{ Dhaka } \\
\hline & Male & Female & Male & Female \\
\hline Psychosocial disabilities & 4 & 8 & 2 & 4 \\
\hline Intellectual disabilities & 0 & 2 & 0 & 0 \\
\hline Epilepsy & 1 & 0 & 1 & 0 \\
\hline Other cognitive impairment & 2 & 0 & 1 & 0 \\
\hline
\end{tabular}

Sixteen of these service users (6male, 10 female) were unable to speak on their own behalf, including 11 of the service users with psychosocial disabilities, both of the service users with intellectual disabilities, both of the service users with epilepsy, and the service user with a cognitive impairment resulting from head injury. In each of these instances, a carer was interviewed instead. The majority of carers interviewed were parents of the service users in question ( 3 male, 6 female); however, in some cases the carers were siblings ( 2 male, 2 female); grandparents ( 1 male, 1 female) or a spouse ( 1 male, 0 female) [Table 2].

Carers commonly identified themselves as the head of family and main income source responsible for the service user's treatment. All but one service user lived with family members; the exception was a student who lived in a hostel for his schooling. 
Table 2

Characteristics of carers interviewed on behalf of service users

\begin{tabular}{|lllll|}
\hline & \multicolumn{2}{l}{ Chittagong } & \multicolumn{2}{l|}{ Dhaka } \\
\hline & Male & Female & Male & Female \\
\hline Parent & 2 & 5 & 1 & 1 \\
\hline Grandparent & 1 & 0 & 0 & 1 \\
\hline Sibling & 2 & 1 & 0 & 0 \\
\hline Spouse & 0 & 0 & 1 & 1 \\
\hline
\end{tabular}

Content Analysis

Five overarching categories were identified to structure our analysis: 1 . Explanatory models; 2 . Helpseeking behaviors; 3 . Impact of services; 4 . Challenges and barriers to improving mental health; 5 . Recommendations of users and carers. Results are presented for each of these categories below, with examples from interview transcripts used to illustrate key trends identified through content analysis.

Theme 1: Explanatory models

\section{1.a. Unknown or supernatural causes}

Most interviewees $(n=14)$ did not have any explanation for why a service user had become unwell. For example, one student reported: "Since September 2013 when I was an SSC[Secondary School Certificate]examinee, I was suffering from mental illness. But I don't know why this was happening to me... I had no clue" (ID 53: 21year-old man with cognitive impairment from unknown cause). On the other hand, two participants offered supernatural explanations, i.e. that the service users had been possessed by jinn[demons], as in the below:

There was a cotton tree. The problem started after cutting that tree. She started talking abnormally. She used to cry without any reason. She stopped taking food... She didn't want to go anywhere with us. Then, she started wearing niqab with a burqa[religious attire]. And one day, she left the house without informing us... We found her later.(ID 56: Mother of 18 year-old woman with psychosocial disability)

\section{1.b. Traumatic life events}

Four respondents identified traumatic life events precipitating the onset of illness. These events included the death of a father or husband, abuse and sexual assault, and early child/forced marriage. In the below narrative, a member of the PHRPBD field staff interjects in an interview to help a mother explain what happened to her daughter after being married against her will as a teenager: 
She started behaving like that after her marriage. She was 15 when she got married. She did not want to go to her in-law's house. They [the in-laws] forced her. They took her with them forcibly... just before the wedding, I mean when the groom was on his way to the venue, she started acting abnormal. She started uttering some mantras. Gradually, her problem increased. Maybe she didn't like her husband. Her husband was a handicapped man; she didn't want him. She disliked him... Moreover, she wanted to pursue her education. (ID 46: Mother of 27 year-old woman with psychosocial disability)

In another instance, a carer blamed abuse by a young woman's stepmother for causing the illness: "Her father left her mother and took her with him. Then her stepmother locked her in the house and gave her a frightened life" (ID 67: Grandmother of 20-year-old woman with psychosocial disability). Two participants identified rape as the main factor precipitating the onset of illness, as in this account by a service user:

That year on Eid day, one guest came to our house. He touched my hands and was taking me to have snacks with him. Then suddenly something happened that I didn't want. I wasn't feeling good about this. Since then I changed and the problem developed. (ID 52: 28 year-old woman with psychosocial disability)

\section{1.c. Physical causes}

As opposed to psychologically distressing life events, physical traumas were also reported as a key factor behind some service users' illnesses. Two carers reported that head injuries from accidents (a severe burn, a fall from a building) may have been responsible; for example: "He fell down from the fourth floor. Not on the ground. Luckily, he fell on the third-floor terrace of the opposite building. But he broke his hand completely and also got injured in his head" (ID 48: Father of 22-year-old man with cognitive impairment).

Underlying health conditions, such as epilepsy (in two cases) and stroke (in one case) were also reported. In this interview, it was unclear whether the carer may have also considered his physical violence toward his daughter to have played a role in activating symptoms shared by his brother:

I have a daughter; she also needs care. She is suffering from the same problem just like my brother... we didn't know that she had the same problem. When she was in class three, we identified her problem. One day, I beat her. She started crying and convulsed the same as my brother and fell on the floor. (ID 58: Brotherof 25 year-old man with epilepsy)

Theme 2: Help-seeking patterns

\section{2a. Formal health care}

Participants generally sought care from a number of different formal and informal providers before learning about PHRPBD's mental health camps. Only one service user reported that the mental health camp was her first point of contact with mental health services. Most participants $(n=19)$ reported visiting other health services-sometimes without seeing substantial improvement: "At first in Chondona [sub-district] and from there to Amra Hospital and then in Chittagong Medical College... and then to a Psychiatrist" (ID 51: 18 year-old woman with psychosocial disability).Even at Pabna Hemayetpur Mental 
Hospital (PHMC), Bangladesh's largest psychiatric hospital, service users were not always properly referred into appropriate services, as a PHRPBD field staff member helped a mother to explain:

They admitted her to Pabna Mental Hospital through a broker. But they kept her in a place which wasn't appropriate for her. I mean a proper place. There are so many divisions in Pabna Hospital, but they kept her with drug addicts... for six months.(ID 46: Mother of 27 year-old women with psychosocial disability)

Roughly half $(n=9)$ of the participants who reported visiting other health services said that they went to government-run tertiary hospitals, such as Chittagong Medical College (CMC), PHMC and Shaheed Tajuddin Ahmed Medical College. Five participants said that they visited more locally accessible health services, such as nearby government hospitals or health complexes, private clinics, local doctors or family doctors. Two of these participants visited uncredentialed paramedics who are often treated as doctors in rural areas.

Four service users were seen by a psychiatrist (two at CMC). Three reported that they had been admitted to inpatient care (one at $\mathrm{CMC}$ and two at PHMC) before coming to the camp. Three carers said that they had taken a service user for treatment by a neurologist or neurosurgeon. Only one carer reported that his child had been referred to a specialist at the Autism Care Centre; however, his doctor had advised that there was no need to go if improvements in development were noted, so the appointment was never made:

Then I took him to a doctor, a child specialist. He told me to wait for four years. If he fails [to improve] after four years, then admit him to autism center. But he became normal by the time. His speech and other things became normal within the age of three. He started running with all his energy. (ID 48: Father of 22 year-old man with cognitive disability)

While participants were not specifically asked how long they lived with symptoms before accessing care for the first time, it was clear that many had spent long periods without treatment. According to a field staff member, at least one service user was actively prevented from accessing care by her in-laws: "She remained untreated in her husband's home for 11 months... after 11 months she was admitted in to Pabna Mental Hospital for six months" (ID 46: Mother of 27year-old woman with psychosocial disability).

\section{2.b. Traditional healing}

Eight participants reported that traditional healers(religious person, ojha, kabiraj, boiddo) were consulted prior to attending the mental health camp. In some cases, multiple healers were visited:

My uncle-in-law was a healer, and we took her [the service user] to show him. After that, we were unable to feed her for five to seven days. Water was flowing out of her mouth. After listening to other people, we took her to the Dohazari [where the healer lives].(ID 56: Mother of 18year-old woman with psychosocial disability) 
Several participants $(n=6)$ reported disappointment with the services of traditional healers. One carer said there was no change after treatment by healers. Two service users complained that they had wasted time and money on traditional healers in hopes that they might be able to find a cure; one had spent the equivalent of nearly $\$ 3,000$ US: "Went to religious leaders for 10 years. I mean Hujur, Badiya [priest/healer], almost 2.5 lakhs taka was spent"(ID 60: 39 year-old man with psychosocial disability).One carer reported skepticism about healing practices, even as they were being performed on his son:

Initially when it started, I mean the convulsions [epilepsy], we were roaming around here and there. He [traditional healer] came here. Then he inspected him [service user] and treated him with a broomstick. But we didn't believe him. We didn't allow him to give him Tabij [amulet]. These are actually of no use.(ID 64: Father of 18 year-old man with epilepsy)

\section{2.c. Mental health camp}

Many participants $(n=10)$ learned of PHRPBD's mental health camps through the outreach of its field staff, self-help group members, "apex body" (an umbrella group for local self-help groups) or partners in the health system. Several participants $(n=16)$ noted how important the support of field staff was in facilitating access to PHRPBD's services. Here, a man interjects in his sister's interview to explain: "Then we heard about the [self-help] group, and then they [field staff] supported us with many things. We visited doctors through their help. And also brought her [with the carer] to their official programs" (ID 52:28-yearold woman with psychosocial disability).

Other participants $(n=15)$ learned of the camp indirectly through word-of-mouth from community members such as teachers, local police officers, social welfare officers, political party members and other recipients of the camp's services. A few of these respondents (CG: $n=2 ; S U: n=1$ ) said that service users were brought to the camp with help from family members and neighbors:

My brother told me about Asharalo [name of the camp]. They gave us different kinds of supports, they told us to never think that we are mentally ill persons and [therefore] unable to do anything. They gave us mental strength. Once I used to feel that I was very weak. Now I feel good. (ID 53: 21year-old man with unknown condition)

Camps were often the entry-point into PHRPBD's self-help groups and other activities, even for those who were already known to the program, as a member of the local field staff explained during an interview with a mother:

We talked about it in the team. We discussed the information in the team... She is our group member plus... we identified her severity of illness... Then when she came to the camp, she got selected as a service user.(ID 46: Mother of27year-old woman with psychosocial disability)

Theme 3: Impact of services

\section{3.a. Mental health care}


One service user felt that there had been no change in his condition after receiving treatment from the camp, and two carers reported that service users had relapsed. However, the majority of participants noted improvements and felt treatment to be beneficial, even though it was mostly limited to medication.

Twenty respondents reported significant improvements, leading a few families $(n=2)$ to stop using physical restraints, as the health worker quoted above commented: "There is a huge change in her! They [family members] used to tie her up... Now she cooperates" (ID 46: Mother of 27-year-old women with psychosocial disability). A carer of another young woman made similar observations: "[We used to restrain her] with [a] chain.... We kept the door closed. Sometimes she disturbed us in [our] work, didn't want to understand. Now she understands if we say [she needs to be quiet] and stays silent" (ID 43: Mother of 17-year-old woman with intellectual disability).

Examples of improvements were in communication and social skills, interpersonal relationships, sleep and general affect: "There are some changes, like she talks with others, interacts and participates in the group meetings. Earlier, in the self-help group meetings she couldn't sit. She used to walk away" (ID 49: Sister of 22-year-old woman with psychosocial disability). In another instance, small changes resulting from treatment opened the door to more substantial and positive life changes resulting from a new work opportunity:

After taking medicine, a few developments were noticed. 'Changes' means, he didn't want to talk or share anything with us before. He used to watch TV all the time and didn't talk much. After he started working at [name of electronics store], the improvement in his behavior began. I know that he won't get salary but there were 10-15 people working with them... because of working together, now he feels free and shares things. (ID 48: Father of 22-year-old man with cognitive impairment)

Distressing symptoms such as wandering, aggression and epileptic seizures were also reported to have subsided with treatment: "She used to cry and scream [in her sleep] ... she used to hit people with whatever she has... it was more intense before [she was given the treatment]" (ID 43: Mother of 17-yearold woman with intellectual disability); "She is better than before. 'Better' means, earlier she used to say a lot of 'akrum','makrum' [incoherent speech], used to sing and go here and there. Eventually, she became calm. Now she sits at home" (ID 61: Mother of 25-year-old women with psychosocial disability). Another carer reported: "Sir [doctor from the camp] gave me medicine and after taking that medicine, things were almost under control. His convulsions stopped” (ID 58: Brother of 25-year-old man with epilepsy).

\section{3.b. Social and economic support}

PHRPBD subsidizes the cost of medication for some participants in vulnerable situations: "They [the camp authority] offered us medicine for one month" (ID 56: Mother of 35 year-old woman with psychosocial disability).Seven respondents reported that they had received some of their medication from the camp free of charge, though they were aware that this support would not be permanent and many felt that it was not sufficient as-is: "I got it [medicines] from camp, most probably for one month and highest two months" (ID 45: 38 year-old woman with psychosocial disability). 
Other types of support accessed via PHRPBD included disability allowance, education support and vocational training. Seven participants reported that service users were receiving disability allowance, which is paid by the government but often difficult to access without the aid of more experienced members of the self-help group and field staff:

We tried Apa[addressing a woman] but could not get it [allowance]. Not even in seven years! So, she didn't receive the disability allowance. She is trying to get eligibility for the allowance. And I mentioned that there are not sufficient allocations for disability allowance. So, I also raised this issue at district level. It is not high enough. The government allocated [budget for] two disabled persons [to receive allowance] in each ward five years back. Now it has increased but still not sufficient. (ID 49: Sister of 22-year-oldwomen with psychosocial disability)

Three participants explained that service users were also receiving support to exercise their right to education: "When I asked for a disability certificate from the councilor, he gave one... It helped him [the service user] to sit for the exams and further studies" (ID 48: Father of 22year-old man with cognitive impairment). A mother of a PHRPBD service user described how the self-help group intervened when another one of her children with an intellectual disability was being discriminated against by a teacher:

The teacher said he doesn't read or write, always [just] sits there, [so] give him home schooling. I told her that he doesn't study at home, that's why I bring him here. If it is not today, maybe he will learn to read and write tomorrow, he will learn at least something. After all that, when he failed at exams, my elder daughter went to the school. The teacher said,'I have told your mother to take him home, he doesn't study here, give him home schooling.' I told [the self-help group] about it here and the group went to the school...I'm feeling good after seeing the change of my son. (ID 43: Mother of 17 year-old girl with cognitive impairment)

The emotional support provided by self-help groups was seen as important by most participants $(n=17)$, including both service users and carers. Here, one woman contrasts the difficulty of her relationships at home with the positive relationships she has established with self-help group members: "They are cheerful. I was beaten by my sisters-in-law and brothers, but here I am getting medicines and everyone loves me a lot" (ID 45: 38-year-old woman with psychosocial disability). The mother quoted above also remarked on the change self-help groups had made in carers' lives:

If anybody says something [cruel] to them [my children] or hits them or does something to them, they [the self-help group] tell me to report to them, call them. They inspire me and give me courage, tell me not to neglect [my children], this type of courage. (ID 43: Mother of 17 year-old girl with intellectual disability)

Theme 4: Challenges and barriers to improving mental health

\section{4.a. Medication}

Despite a general sense of positivity regarding the benefits of treatment, side effects of medication were described as a challenge by six participants. Common complaints were feeling drowsy or lethargic after 
taking medication, though some side effects were more severe: "We gave him the dose of medicine. We noticed his legs swelled. My mother started crying" (ID 58: Brother of 25-year-old man with epilepsy).

Further, the cost of treatment was described as a barrier by several participants $(n=11)$, and sometimes led to incomplete or missed dosages, despite the partial subsidies offered by PHRPBD to some service users: "At times, I could not bring medicines because of financial problems. Almost 15 days it was stopped. After stopping medicine, he started talking abnormally again. 1200 taka after every 15 days is too much for me" (ID 57: Father of 25year-old man with psychosocial disability). These challenges were especially pronounced for those who had not yet been able to access their disability allowance or to attend the mental health camp:

Fees of the doctors range from 500 or 1000 taka. For medicine I have to spend 2000 taka, 2500 taka or sometimes 3000 taka approximately. I can't afford his treatment. I have money problems. I don't have any income, not a single penny at all. If he [the service user] could be given disability allowance, he would be benefitted. If we get free medicine from the doctor, we can feed him. (ID 55: Brother of 35year-old man with psychosocial disability)

Although interviewees did not raise this as a concern, it is possible that overprescribing may have contributed both to the side effects and high cost of treatment. Several participants $(n=6)$ were prescribed three or more different medications at the same time-up to five, in one case: "At first he [psychiatrist] gave five types of medicine... after one week he reduced it to four types... [now it is] two or three types" (ID 57: Carer of 25-year-old with psychosocial disability).

Some carers explained that they had very little knowledge of mental health or how best to treat the service user, and yet still took it upon themselves to make decisions about service users' medication, without consulting health professionals. One carer gave his brother's medication to his young daughter when she started having similar symptoms. Two carers said they stopped the service user's medication, as in the below quote:

He [doctor] didn't say to stop the drug. He said if she [service user] feels good, we should contact him... she won't continue the medication. If we took her to the doctor, he would either reduce the drug dose or discontinue the medication. So we stopped the medicines by ourselves. We didn't take her to the doctor. (ID 56: Mother of 18year-old woman with psychosocial disability)

\section{4.b. Accessibility}

While many participants $(n=14)$ reported that the mental health camp was easily accessible, one service user said that the cost of transport was a barrier. Two carers complained that because the camp was not based in their area, it was more difficult for them to attend. Five carers explained that it was logistically difficult to transport service users who were very unwell, even to a nearby camp, and that service users were often unable to travel on their own: 
After visiting there [camp], she [the service user] is getting better. But it's been a lot of trouble to give her medication. She was behaving abnormally during the medical tests. One day, she lost her way to home and went to the club of Selpata. Then again, she was behaving abnormally. (ID 56: Mother of 18-year-old woman with psychosocial disability)

In especially desperate situations, service users were physically restrained and brought to the camp by force: "After binding his [service user's] hands and feet we have to carry him by vehicle to the camp" (ID 58: Brother of 25-year-old man with epilepsy). Stigma was also a barrier for some. In this same case, where a man was tied up to be taken to camp, the man's brother explained that he didn't want to bring his daughter to the camp or to any other mental health services, as this might affect her marriage prospects:

We discussed about her [service user] problem with our uncle. He forbade us to reveal her disease. He hid, Apa[term for addressing a woman]. My child is very young. She is my daughter, that's why I could not say or reveal. I didn't take her to the hospital for fear of people [learning of her condition]. She is a girl that's why.(ID 58: Brother of 25 year-old man with epilepsy)

\section{4.c. Violence and abuse}

Nearly half of participants $(n=12)$ talked about the stigma and discrimination they faced from their families and communities, who considered them cursed, called them names, and otherwise bullied or isolated them. Sometimes, mistreatment of service users grew violent. There were two reported cases in which service users had been beaten and raped by local men. A member of the field staff helped one carer to explain how this had led to an unwanted pregnancy, and as an unmarried woman the service user faced further stigma and estrangement from her family as well as criticism from community members:

We don't know [who the culprit is] and she also isn't saying anything... She speaks very little and only with her sisters... She doesn't talk about this thing. Gradually she stopped talking with everyone. We are trying to find out the culprit... after this problem when she got pregnant, we went to the government hospital, but it was already three to four months [into the pregnancy]. So the doctor said that abortion is not possible... Now she is five months pregnant... Big problem for them is the community people. How can I explain to you? The community people always disturb her with different types of criticism. The society doesn't want to keep her in this hospital. So, the family wants to send her to some other place for the delivery. After her delivery, then they [family members] can take her. But, the family also wants to send her away because they are ashamed or they can't maintain her.(ID 49:Sister of 22 year-old woman withpsychosocial disability)

As well as sexual violence in the community, domestic violence was also especially prominent among female service users. Although this was not the subject of our questioning, three service users described the violence they faced at home. In one case, physical abuse was intertwined with a service user's struggle to maintain financial autonomy from the rest of her family:

My elder sister-in-law, she is a bad woman. She was our tenant. She took my money, all my earnings from the garments job... My brothers also took my money, beat me and threw me out of the house... His wife 
has also beaten me, held a knife on my throat... My younger brother saved me. (ID 45: 38 year-old women with psychosocial disability)

Theme 5: Recommendations of service users and carers

\section{5.a. Scale-up mental health camps}

As described earlier, many participants felt they had benefitted from the mental health camp, and therefore wanted to see it held more regularly in their own locations and also scaled up nationally so that others in need of mental health care could benefit $(n=10)$ : "If it spreads in the whole area, it will be great... I wish the program spreads widely" (ID 65: Husband of 39-year-old woman with psychosocial disability).

The community thinks that this kind of help is very good for them [service users] and the community also wants more services from them [PHRPBD]. Community people, all kind of disabled people, mentally ill people can easily get this service. So, people think that this type of camp should be arranged on a regular basis.(ID 53:21 year-old man with cognitive impairment from unknown cause)

Implicit in many participants' responses $(n=19)$ however were critiques of PHRPBD's current model of mental health care: that for those who relied on the camps for subsidized treatment, they were too infrequent, and that more follow-ups were needed between camps. To illustrate: "We're in financial trouble. So, if you're arranging a health camp two or three times, it will be good for us" (ID 56: Mother of 18year-old woman with psychosocial disability); "If the team [of field staff] would be well formed, they could work more effectively. Apa [local term for addressing a woman], if our camp becomes easier, that will be great. More follow-up and rapid improvement" (ID 44: Mother of 24-year-old woman with intellectual disability). A man interjected in his sister's interview to explain that services generally are not provided on a regular enough basis: "From this project [there are] different types of support my community people are getting, like my sister. Sometimes the project gave us some medicine, sometimes advice or other services. These services are not constant. It should be regular" (ID 52: 28 year-old woman with psychosocial disability). One carer suggested that the limited number of camps in the area might also place pressure on those from the communities hosting camps, as they become the de facto contact people for those coming from outside PHRPBD's catchment areas:

You see, I am getting treatment in my area. The project you have started is area-based. If anyone gets information from me, they will communicate with me always. If the camp is in every place, it will be easier for everyone to keep in communication with you. Thus, they will be benefitted a lot. (ID 64: Father of 18year-old man with epilepsy)

Another carer also suggested that PHRPBD could use additional outlets to improve communication and raise awareness of their services:

They treat patients, which is helpful to everyone. The way you promote through leaflets is not enough. If you do the same in newspaper and television advertisements more people will get benefited. You can also 
organize health camp two or three times in a year. (ID 57: Father of 25year-old man with psychosocial disability)

\section{5.b. Increase social and economic support}

In addition to those who complained they were not receiving enough support with the cost of medicines $(n=2)$, a few participants $(n=4)$ requested that PHRPBD increase its employment and educational support (including vocational training) for service users, for example: "If you donate some of the money, it will be good. Help her to give a flower shop. It will be beneficial for her" (ID 67: Grandmother of 20 yearold woman with psychosocial disability).Participants argued that by becoming more independent, service users could meet their own expenses, reducing the burden on the program as well as their families: "There are many people who are disabled and mentally ill persons, if there is an opportunity to give them any training, then they are not being a burden for their family" (ID 53: 21 year-old man with cognitive impairment from unknown cause); "If we get jobs through this group, this would be better. I am a visually impaired man, but if my son gets good education, he will get a job, that will bring about a big change" (ID 55: Brother of 35 year-old man with psychosocial disability).In terms of social support, two carers recommended more recreational activities for service users and to find ways to increase their involvement during group meetings: "He wants to do something like this...like, singing, dancing. If any marriage ceremony is held here, then he wants to dance with others. If you can arrange some recreation, then there are some chances to be cured" (ID 63: Mother of a 25-year-old man with psychosocial disability).

\section{Discussion}

Key findings from our analysis of the experiences and perceptions of Bangladeshi carers and service users are related to their explanatory models and health-seeking behaviors, the impact of the PHRPBD program, and barriers as well as recommendations they gave for further improvement.

The majority of respondents gave no explanation for why service users had become unwell in the first place. However, some attributed the onset of illness to physically and/or emotionally traumatic events that occurred at some point in the service users' lives. Examples included child forced marriage and experiences of sexual violence and domestic abuse. These findings are supported by previous qualitative and epidemiological studies of women's mental health in Bangladesh and in other countries around the world(21-23). For example, a study of female garment workers in Bangladesh found that those who had experienced more than three traumatic life events were 11.25 times more likely to screen positive for posttraumatic stress disorder, and the mean number of traumatic life events experienced by women in this population was 4.9 (24). A few respondents identified supernatural forces, such as black magic and possession by jinn (demons), as contributing to the illness of service users. This finding is also supported by a large body of literature on culture and mental health in Bangladesh $(9,25)$.

Participants sought care from a variety of sources before accessing PHRPBD's services. These included both medical facilities such as tertiary government hospitals and specialized mental health facilities, as well as informal providers such as non-credentialed village doctors and traditional healers. A situation 
analysis on mental health in Bangladesh posits that mental health conditions are primarily viewed as spiritual issues, and that this impacts health-seeking behaviors of people with mental health conditions and their carers (26). Other studies from South Asian contexts have commented on the popularity of informal providers particularly in rural areas, due to their easy accessibility and claims to cure mental health conditions(27). Lack of awareness of the potential severity of mental health conditions has also been identified as a reason why traditional healers are commonly consulted $(6,28)$. Reliance on informal providers is frequently blamed by mental health professionals in Bangladesh for contributing to delays in accessing formal services $(6,9,29-31)$.

Another key finding is that many participants noted improvements in service users' symptoms (e.g. speech and behavioral patterns), social relationships (e.g. social interactions), and daily functioning (e.g. household chores and self-care), which they attributed to the services provided through PHRPBD. Selfhelp groups were also seen as beneficial sources of social, emotional and practical support to carers. While there is currently little research from LMICs on the effectiveness of CBR for people with psychosocial disabilities, previous studies in Ethiopia and India have shown promising results for these types of programs(32-35).

Despite the overall positive feedback on PHRPBD's services, participants identified a number of challenges that remain. Stigma, discrimination and human rights abuses (including forced treatment and restraint) persist and are compounded by issues of gender inequality. In addition to forced marriage and the physical and sexual violence against women described above, we identified at least one instance where a male family member was allowed to access the program's mental health camp, while a female family member with the same condition was not, due to stigma and its potential to affect her perceived marriageability. Previous studies have observed that in the Bangladeshi context, women are less likely to receive mental health care $(6,31)$, and this may be one reason why. Another troubling case observed in our study was of a woman with a psychosocial disability who was sexually assaulted in the community, resulting in an unwanted pregnancy and further social abandonment. Sexual violence against women with disabilities who are then denied access to health care as well as justice has been reported in other LMICs, though this is an understudied issue $(36,37)$.

Participants also identified barriers specific to the program itself, which should be taken into consideration by its organizers. First, the mental health camps that offer community-based diagnosis and treatment are only held annually. Given the need for regular review and the limited medication supplied, this is a valid criticism. Second, PHRPBD subsidizes the cost of treatment for families in vulnerable situations, but some families still found it to be a significant financial burden. While the program does have an economic component, several participants explained that they wanted more economic opportunities so that they could pay for their own treatment as well as other expenses. Finally, participants felt that the program should be replicated in more communities and even scaled up nationally to improve accessibility and sustainability over the long-term.

\section{Limitations}

Page 17/24 
While qualitative research is subjective by nature and never generalizable, the current study has several limitations which may have increased the risk of bias. First, participants were purposively selected with guidance from PHRPBD staff members. It is possible that those with more positive experiences of the program could have been chosen. Relatedly, program staff and participants do not always distinguish between epilepsy, psychosocial and intellectual disabilities, and other cognitive impairments; consequently, this was a heterogenous sample. There is recall bias inherent to any study involving retrospective reporting, but this may be particularly pronounced when participants have experienced cognitive impairments. Carers spoke for those who were unable to communicate on their own behalf, and this is also a potential source of bias. The fact that relatively few participants reported visiting traditional healers highlights the likelihood of social desirability bias, which could have been influenced by the presence of the PRPBD staff who aided in translation during interviews. Finally, this study was not resourced for back-up audio-recording in case of technical issues (which ultimately resulted in the exclusion of two interviews from this analysis), back-translation of interview guides and transcripts, or the use of qualitative research software to support the process of analysis. We would recommend a more rigorous and ideally mixed-methods study to follow this one, assessing PHRPBD's effectiveness and also exploring key themes such as explanatory models and health-seeking behaviors in more depth.

\section{Conclusion}

This study adds to the limited body of qualitative research on the experiences of people with psychosocial disabilities, intellectual disabilities, epilepsy and other cognitive impairments in Bangladesh, reinforcing previous findings related to explanatory models and health-seeking behaviors while providing new insights into the impact of a CBR program in this context. The generally positive feedback of service users and carers suggests that CBR may indeed be a useful approach to increase access to health and social services in Bangladesh. Further, the self-help groups at the center of this program appear to have benefits in terms of promoting both the empowerment of people with disabilities and peer-to-peer social and emotional support. However, this program is not without its limitations, some of which are the products of broader issues within the mental health system (e.g. shortage of mental health specialists; cost of medications) and others of social and cultural issues (e.g. poverty; gender inequality; mental health stigma, discrimination and violence). More research is needed to formally evaluate this and other CBRprogramsin the global south that are working to improve mental health, ideally using mixed methods to triangulate findings from qualitative research.

\section{Declarations}

\section{Ethical Approval and Consent to participate:}

Ethical approvals were secured from the London School of Hygiene and Tropical Medicine (Ref. 14597) and the Bangladesh Medical Research Council (Ref. 14826092018) before any data were collected. 


\section{Consent for publication:}

Not Applicable

\section{Availability of supporting data:}

Not Applicable

\section{Conflict of interest:}

The authors of this study declared that they have no conflict of interest.

\section{Funding Sources:}

Fieldwork for this study was funded through a grant by CBM International to the London School of Hygiene and Tropical Medicine.

\section{Authors' contributions}

GR conceptualized the study, designed data collection and the field implementation, conducted the interviews and collected the data. KK trained FS and RA to translate and transcribe the interviews. KK coded and analysed the data and wrote the manuscript with the assistance of FS and RA. GR and KK intensively supported in developing the concept of the study and reviewing the manuscript. JE and GR reviewed the analysis of the data, editing and finalizing the manuscript. THD, JE and TK supported in critical reviewing the manuscript. All authors read and approved the final manuscript.

\section{Acknowledgments}

We are grateful to the study participants for sharing their stories with us. We would also like to thank the staff of CDD and partner organizations of PHRPBD who made this research possible-especially Rezaul Alam, who coordinated the fieldwork component. We acknowledge the contribution of four student researchers in the transcription and translation of the interviews: Dr. Rudbar Mahmood (RM), Dr. Lisanul Hasan (LH), Dr. Nadia Sultana Dolly (ND) and Dr. MahmudaNajnin (MN). Finally, we wish to thank the coinvestigators and advisory board members who helped to conceptualize the CBR case study project from which this study derived: Dr. Laura Asher, Dr. Alex Cohen, Dr. Joerg Weber, Soumana Zamo and Petra Kiel. icddr,b is grateful to the governments of Bangladesh, Canada, Sweden and the UK for providing unrestricted support. 


\section{References}

1. Bank TW. The World Bank In Bangladesh Washington, D.C.2020 [Available from: https://www.worldbank.org/en/country/bangladesh/overview.

2. Chowdhury AMR, Bhuiya A, Chowdhury ME, Rasheed S, Hussain Z, Chen LC. The Bangladesh paradox: exceptional health achievement despite economic poverty. The Lancet. 2013;382(9906):1734-45.

3. Commission BP. Millennium development goals: Bangladesh progress report-2015. Dhaka: Bangladesh Planning Commission; 2015.

4. IHME. The Institute for Health Metrics and Evaluation (IHME), Country Profiles: Bangladesh University of Washington2019 [Available from: http://www.healthdata.org/bangladesh.

5. WHO. National Mental Health Survey of Bangladesh. 2018-2019.

6. Hossain MD, Ahmed HU, Chowdhury WA, Niessen LW, Alam DS. Mental disorders in Bangladesh: a systematic review. BMC Psychiatry. 2014;14(1):216.

7. Organization WH. Mental Health Atlas, 2017. 2017.

8. WHO. Mental Health Atlas country profile 2014: Bangladesh. 2014.

9. Nuri NN, Sarker M, Ahmed HU, Hossain MD, Beiersmann C, Jahn A. Pathways to care of patients with mental health problems in Bangladesh. International journal of mental health systems. 2018;12(1):39.

10. WHO. WHO-AIMS report on mental health system in Bangladesh. 2007.

11. Hosain GM, Chatterjee N, Ara N, Islam T. Prevalence, pattern and determinants of mental disorders in rural Bangladesh. Public Health. 2007;121(1):18-24.

12. Rana J. Mental health in bangladesh: yet to be explored. Global mental health and therapeutic assemblages: concepts, controversy and necessary tensions; University of Sheiffield, UK2018.

13. WHO. Bangladesh health system review: Manila: WHO Regional Office for the Western Pacific; 2015.

14. Collins PY, Patel V, Joestl SS, March D, Insel TR, Daar AS, et al. Grand challenges in global mental health. Nature. 2011;475(7354):27-30.

15. WHO. Supplementary booklet. Community-based rehabilitation: CBR guidelines. Geneva: World Health Organisation; 2010.

16. Ryan G, Miguel-Esponda G, Castro P. Integration of mental health and psychosocial disabilities into community-based rehabilitation and inclusive development in low- and middle-income countries: Case studies from Bolivia, Bangladesh and Nigeria. [Internal Report]. In press 2019.

17. Ryan G. Field Visit to a Community-Based Rehabilitation Programme Integrating People with Psychosocial Disabilities in Bangladesh. Bensheim: CBM International; 2019.

18. Kim H, Sefcik JS, Bradway C. Characteristics of Qualitative Descriptive Studies: A Systematic Review. Res Nurs Health. 2017;40(1):23-42. 
19. Cohen A, Eaton J, Radtke B, De Menil V, Chatterjee S, De Silva M, et al. Case study methodology to monitor and evaluate community mental health programs in low-income countries. London: CBM international and London School of Hygiene and Tropical Medicine; 2012.

20. Ryan G. Field Visit to a Community-Based Rehabilitation Programme for People with Psychosocial Disabilities in Akwa Ibom, Nigeria. Bensheim: CBM International; 2018.

21. Islam MM, Jahan N, Hossain MD. Violence against women and mental disorder: a qualitative study in Bangladesh. Tropical medicine health. 2018;46(1):5.

22. Kopinak JK. Mental health in developing countries: challenges and opportunities in introducing western mental health system in Uganda. International journal of MCH AIDS. 2015;3(1):22.

23. Wondie Y, Zemene W, Reschke K, Schröder H. Early marriage, rape, child prostitution, and related factors determining the psychosocial effects severity of child sexual abuse in Ethiopia. Journal of child sexual abuse. 2011;20(3):305-21.

24. Fitch TJ, Yu X, Chien L-C, Karim MM, Alamgir H. Traumatic life events and development of posttraumatic stress disorder among female factory workers in a developing country. International journal of social psychiatry. 2018;64(4):351-8.

25. Mullick MS, Khalifa N, Nahar JS, Walker D-M. Beliefs about jinn, black magic and evil eye in Bangladesh: the effects of gender and level of education. Mental Health Religion Culture. 2013;16(7):719-29.

26. Islam A, Biswas T. Mental health and the health system in Bangladesh: situation analysis of a neglected domain. Am J Psychiatry Neurosci. 2015;3(4):57-62.

27. Chowdhury A, Chakraborty A, Weiss MG. Community mental health and concepts of mental illness in the Sundarban Delta of West Bengal, India. Anthropology Medicine. 2001;8(1):109-29.

28. Islam H, Noman S, Shaheed A, Chowdhury N. Referral pattern of patients to a psychiatric outpatient clinic of Dhaka city. Bang J Psychiatry. 2008;22(1):22-8.

29. Burns JK, Tomita A. Traditional and religious healers in the pathway to care for people with mental disorders in Africa: a systematic review and meta-analysis. Soc Psychiatry Psychiatr Epidemiol. 2015;50(6):867-77.

30. Gureje O, Acha R, Odejide O. Pathways to psychiatric care in Ibadan, Nigeria. Trop Geogr Med. 1995;47(3):125-9.

31. Rahman A, Khan M, Sarkar M, Firoz A, Karim M, Alam M, et al. Study of Morbidity and Referral System Psychiatric Private Practice. Bang J Psychiatry. 2006;20(2):43-9.

32. Asher L, Hanlon C, Birhane R, Habtamu A, Eaton J, Weiss HA, et al. Community-based rehabilitation intervention for people with schizophrenia in Ethiopia (RISE): a 12 month mixed methods pilot study. BMC Psychiatry. 2018;18(1):250.

33. Chatterjee S, Naik S, John S, Dabholkar H, Balaji M, Koschorke M, et al. Effectiveness of a community-based intervention for people with schizophrenia and their caregivers in India (COPSI): a randomised controlled trial. The Lancet. 2014;383(9926):1385-94. 
34. Chatterjee S, Pillai A, Jain S, Cohen A, Patel V. Outcomes of people with psychotic disorders in a community-based rehabilitation programme in rural India. The British Journal of Psychiatry. 2009;195(5):433-9.

35. Iemmi V, Blanchet K, Gibson LJ, Kumar KS, Rath S, Hartley S, et al. Community-based rehabilitation for people with physical and mental disabilities in low-and middle-income countries: a systematic review and meta-analysis. Journal of Development Effectiveness. 2016;8(3):368-87.

36. Barriga SR. "As if we weren't human": Discrimination and violence against women with disabilities in Northern Uganda. 2010.

37. Hughes K, Bellis MA, Jones L, Wood S, Bates G, Eckley L, et al. Prevalence and risk of violence against adults with disabilities: a systematic review and meta-analysis of observational studies. The Lancet. 2012;379(9826):1621-9.

\section{Appendix}

\section{Appendix 1a. Interview Guides (English)}

Discussion guide for beneficiaries:

CBR Case Study Interviews

*Remember: Indicate sex and whether service user/carer on interview notes

1. Could you tell me a little bit about yourself? [For carers, ask these questions and then ask the same about the service user]

1. Age

2. Occupation

2. How was your journey here today to receive services?

1. How long does it usually take you to come here?

2. What mode of transportation do you use?

3. Does someone normally come with you? Why or why not?

4. How much does it cost? Is that affordable?

5. Do you often encounter difficulties getting here?

3. What is the problem that you're coming to services for? [For carers, ask these questions about the service user]

1. How long have you had the problem?

2. Did people treat you any differently when you started having the problem?

4. Can you tell me a little bit about the services you use here? 
1. How did you first learn of these services? What made you decide to come?

2. How long have you been using these services?

3. What normally happens here when you come for services?

4. Are you always able to come to services when you need to? Why or why not?

5. Are you always able to afford these services? Why or why not?

6 . Are you always able to take all of the medications that are prescribed? Why or why not?

5. What other services have you gone to for this problem?

1. Have you ever gone to a spiritual or traditional healer? Why or why not?

2. Have you ever gone to any other health services? Why or why not?

3. Are there any other services that you are using currently? Why or why not?

6. What impact do you think this service has had on you? On your family? On your community?

1. Do you have any recommendations of things that could be done better or differently, to improve these services?

\section{Appendix 1b. Interview Guides (Bangla)}

Q

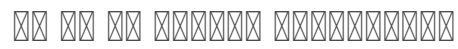

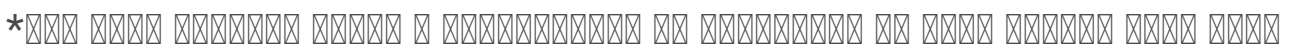

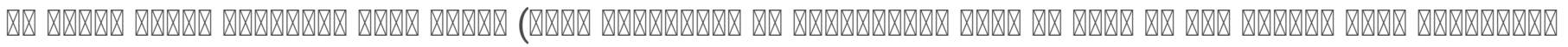
Q

Q

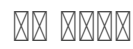

Q

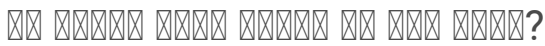

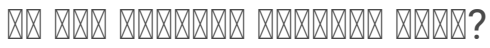

财

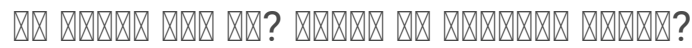

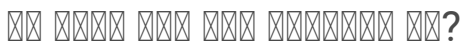




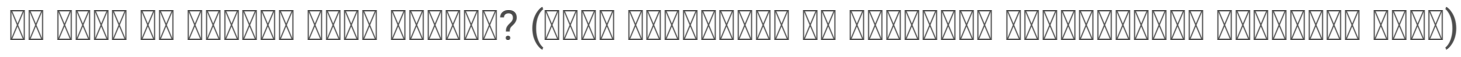

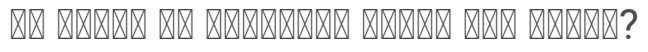

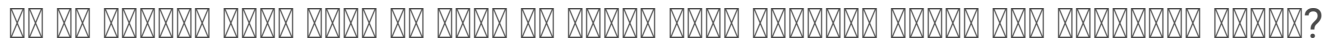

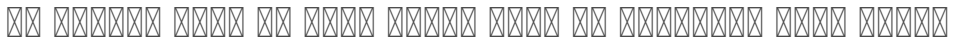

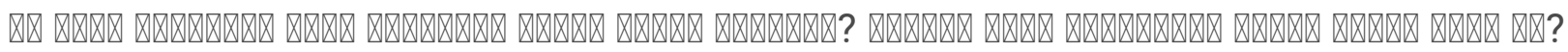

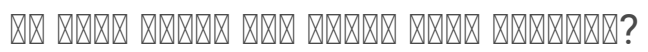

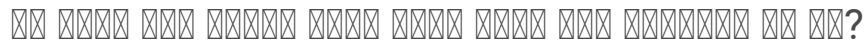

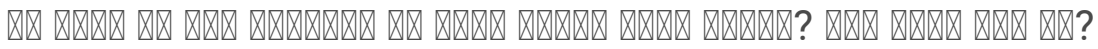

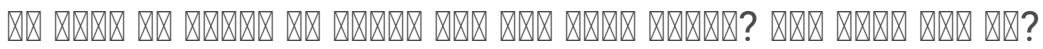

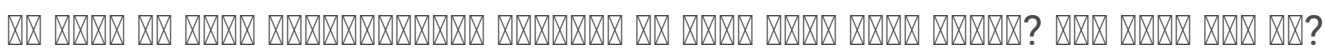

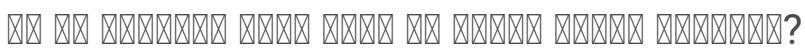

Q

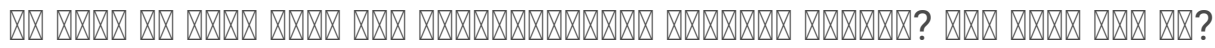

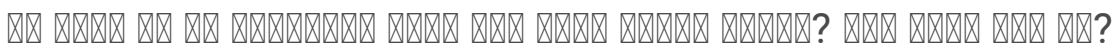

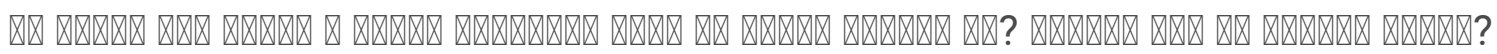

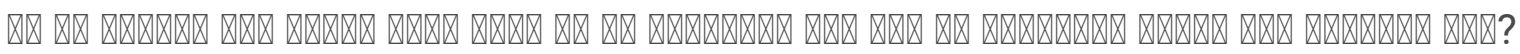

